Brit. F. vener. Dis. (1970) 46, 488

\title{
Gonorrhoea in Edinburgh
}

\author{
D. H. H. ROBERTSON AND D. D. HOSIE
}

From the Department of Venereal Diseases, Royal Infirmary, Edinburgh, and the Department of Bacteriology, University of Edinburgh

In the course of prevalence studies carried out by members of the Medical Research Council Unit for Epidemiological Studies in Psychiatry in Edinburgh, it was observed that the rates of illness for municipal wards of the city showed marked differences. A statistically significant relationship between various manifestations of social pathology such as juvenile delinquency and overcrowding was shown to occur. There was a connection between a high rate of selfpoisoning and a high rate of cruelly-treated children (Philip and McCulloch, 1966).

It has also been observed that certain areas of a city have more serious venereal disease problems than others. In metropolitan Sydney, for example, in 1965, in a survey of venereal disease, it was found that the highest concentration occurred near the harbour and in parts adjacent to the city proper but that no particular area could claim immunity to the disease (Adams, 1967). In Edinburgh, a preliminary examination of the distribution of sexually transmissible disease showed that some areas had a greater incidence than others (Gill and Gould, 1967). This paper presents the results of the analysis of data for the calendar year 1967, as an epidemiological study of sexually transmissible disease in general and of gonorrhoea in particular within the City of Edinburgh.

\section{Material and methods}

\section{ACCURACY OF DIAGNOSIS}

The diagnosis of gonorrhoea in males was made on the basis of microscopy confirmed by culture in the majority of cases. In a sample of 114 consecutive cases diagnosed by the microscopical appearance of a Gram-stained film, culture was attempted in 112. Neisseria grew in 106 ( 94.6 per cent.) and Neisseria gonorrhoeae was identified by fermentation tests in 101 ( $90 \cdot 2$ per cent.).

Received for publication February 26, 1970
Assessment of accuracy of diagnosis of gonorrhoea in women is a more difficult problem. The clinician is often under pressure of work and may subconsciously resolve doubtful microscopic findings into positive findings when he knows that his patient has had recent intercourse with a male who has attended with gonorrhoea. In cases of doubt there is justification in treating the patient as there are often other considerations, such as the risk of salpingitis, the patient's tendency to default, or the possibility of reinfection of a consort. Some diagnoses are therefore made on epidemiological grounds when repeated examinations by cultures are not considered feasible. In 1967, in a series of 68 consecutive cases diagnosed as gonorrhoea in women, culture was attempted in 67 ; Neisseria colonies were found in 53 (79 per cent.) of those in which culture was attempted and Neisseria gonorrhoeae was identified in 51 ( $76 \cdot 1$ per cent.) of the total cultures.

\section{DATA ON SEXUALLY TRANSMISSIBLE INFECTIONS}

The reported incidence of venereal disease in some cities may be notoriously low (Adams, 1967), but our data on sexually transmissible infections from the Edinburgh Royal Infirmary are considered to give a reliable estimate of the true incidence in those who presented for medical attention. Our opinion on the data of this study is based on a conclusion of a Working Party of the Standing Medical Advisory Committee of the Scottish Health Service Council (British Cooperative Clinical Group, 1968). This committee showed that in 1965,10 to 12 per cent. of the total of new cases in the South-East of Scotland might be treated privately; this opinion was based on the results of an enquiry held in the South-East of Scotland which includes Edinburgh, when 85 per cent. of 1,235 general practitioners replied to a questionnaire asking for information about the number of patients with gonorrhoea seen during the period April 1 to June 30, 1964. The present authors consider that there have been no material changes in the practices of doctors in this area since that time.

Data were obtained by one of us (D.H.H.R.) from the records of the Out-Patients Clinic at the Edinburgh Royal Infirmary and only data on the totals of each age group in each city ward were made available for this study. This process ensured confidentiality, the identification of 
any individual or of any address being impossible. For the purposes of this study members of the armed forces and juveniles in custodial institutions such as remand homes or approved schools have been excluded. Data referring to such institutions have already been published (Robertson, 1969; Robertson and George, 1970).

A subsidiary clinic for males is situated near the dock gates at Leith within the electoral ward of Central Leith (No. 19). This clinic is primarily for merchant seamen and is open only for limited periods, but some of those attending are residents of Edinburgh, and, as the data referring to them have not been included in the main study, the relevant information has been added as Appen$\operatorname{dix}$ A (see p. 497).

In this epidemiological study the total of new patients together with those returning after a re-exposure to infection are referred to as 'Total Cases'. This figure includes a wide variety of infections, such as moniliasis, trichomoniasis, genital warts, Herpes virus hominis, infections of the genitalia, and non-specific infections, as well as gonorrhoea and syphilis, and it also includes those who have come for medical advice after exposure to a risk of infection. 'Total Cases of Gonococcal Infections' include first infections as well as re-infections.

ESTIMATED POPULATION OF ELECTORAL WARDS IN EDINBURGH FOR 1967

An estimate of the population was required before the rates for sexually transmissible disease could be calculated. As there had been no census for that year it was necessary to prepare such an estimate.

A population census of Great Britain was taken on April 23, 1961, and the data referring to Edinburgh were published in 1963 (Registrar General, 1963). Since that time changes in the distribution of population have occurred through clearance, rebuilding, and natural causes. An estimate of the population of Edinburgh in 1967 was prepared for this study by applying the percentage population change observed in the roll of each electoral ward of the City between 1961 and 1967 (Table I) to the population of each age group of the 1961 census, on the assumption that the changes observed in the electorate were uniform throughout the population as a whole.

The estimates for the various age groups are tabulated by sex in Appendix B (see pp. 496-7). The population structure according to sex and age for each electoral ward is illustrated for males and females in Figs 1 and 2 (overleaf).

It should be noted that the large changes between 1961 and 1967 observed for Ward 22 Portobello (minus 26.2 per cent.) and for Ward 23 Craigmillar (plus 46.6 per cent.) were due in part to changes in the ward boundaries in 1966.

\section{Results}

The population histograms for Edinburgh show a relatively large excess of elderly women, which is partly due to the high loss of males during the first world war. In some parts of the city this predominance of elderly females is more notable than others.
TABLE I Changes in the electoral roll between 1961 and 1967

For this data the authors are indebted to A. Macdonald, Esq., City Assessor, Edinburgh

\begin{tabular}{|c|c|c|c|c|}
\hline \multirow[b]{2}{*}{ Municipal ward } & \multirow{2}{*}{$\begin{array}{l}\text { Ward } \\
\text { no. }\end{array}$} & \multicolumn{2}{|c|}{ Electoral roll } & \multirow{2}{*}{$\begin{array}{l}\text { Percentage } \\
\text { increase }(-) \\
\text { or } \\
\text { decrease }(-\end{array}$} \\
\hline & & 1961 & 1967 & \\
\hline St. Giles & 1 & 13,237 & 10,702 & $-19 \cdot 2$ \\
\hline Holyrood & 2 & 10,734 & 8,029 & $-25 \cdot 2$ \\
\hline George Square & 3 & 11,267 & 10,178 & $-9 \cdot 7$ \\
\hline Newington & 4 & 16,530 & 15,823 & $-4 \cdot 2$ \\
\hline Liberton & 5 & 19,530 & 21,461 & +9.8 \\
\hline Morningside & 6 & 13,160 & 12,820 & -2.5 \\
\hline Merchiston & 7 & 11,827 & 11,232 & $-5 \cdot 0$ \\
\hline Colinton & 8 & 16,831 & 19,040 & $+13 \cdot 1$ \\
\hline Sighthill & 9 & 15,531 & 14,588 & -6.0 \\
\hline Gorgie-Dalry & 10 & 14,646 & 13,584 & $-7 \cdot 2$ \\
\hline $\begin{array}{l}\text { Corstorphine } \\
\text { Murrayfield- }\end{array}$ & 11 & 15,237 & 16,558 & $+8 \cdot 6$ \\
\hline Cramond & 12 & 14,869 & 19,304 & $+29 \cdot 8$ \\
\hline Pilton & 13 & 16,039 & 18,075 & +12.6 \\
\hline St. Bernards & 14 & 17,815 & 17,196 & -3.4 \\
\hline St. Andrews & 15 & 11,238 & 8,238 & -26.6 \\
\hline Broughton & 16 & 12,872 & 12,410 & -3.5 \\
\hline Calton & 17 & 11,843 & 10,858 & -8.4 \\
\hline West Leith & 18 & 12,047 & 11,532 & $-4 \cdot 3$ \\
\hline Central Leith & 19 & 12,975 & 11,163 & -14.0 \\
\hline South Leith & 20 & 13,895 & 12,993 & -6.5 \\
\hline Craigentinny & 21 & 15,138 & 14,524 & $-4 \cdot 1$ \\
\hline Portobello & 22 & 18,276 & 13,495 & $-26 \cdot 2$ \\
\hline Craigmillar & 23 & 9,963 & 14,614 & +46.6 \\
\hline Total & & 325,500 & 318,417 & $-2 \cdot 2$ \\
\hline
\end{tabular}

Some city wards, such as St. Giles, St. Andrews, and Calton, have small populations; these form the centre of the city in which much redevelopment is being carried out.

DISTRIBUTION ACCORDING TO AGE AND SEX (TOTAL CASES ATTENDING CLINIC AND TOTAL CASES OF GONORRHOEA)

During 1967 there were 971 new and returned male cases (Total cases), and of these 240 (24.8 per cent.) were cases of gonorrhoea. There were 529 new and returned female cases (Total cases), and of these 159 (30.0 per cent.) were cases of gonorrhoea. In the city as a whole for the 15 to 44 year age group, the rate for gonorrhoea is 1.7 per 1,000 for females and $2 \cdot 7$ for males.

These rates are shown in Fig. 3 (overleaf), where it is seen that virtually all cases occur within the age group 15 to 44 years and that the highest rate occurs in the 20 to 24 year age group. The rate is higher in females than in males in the 15 to 19 year age group, but in every other age group the rate is higher in males than in females.

DISTRIBUTION ACCORDING TO DOMICILE (TOTAL CASES ATTENDING CLINIC AND TOTAL CASES OF GONORRHOEA) The distribution is shown in Fig. 4 for males and in Fig. 5 for females. Where the rates have been ob- 


\section{ESTIMATED MALE POPULATION OF EDINBURGH(1967)}

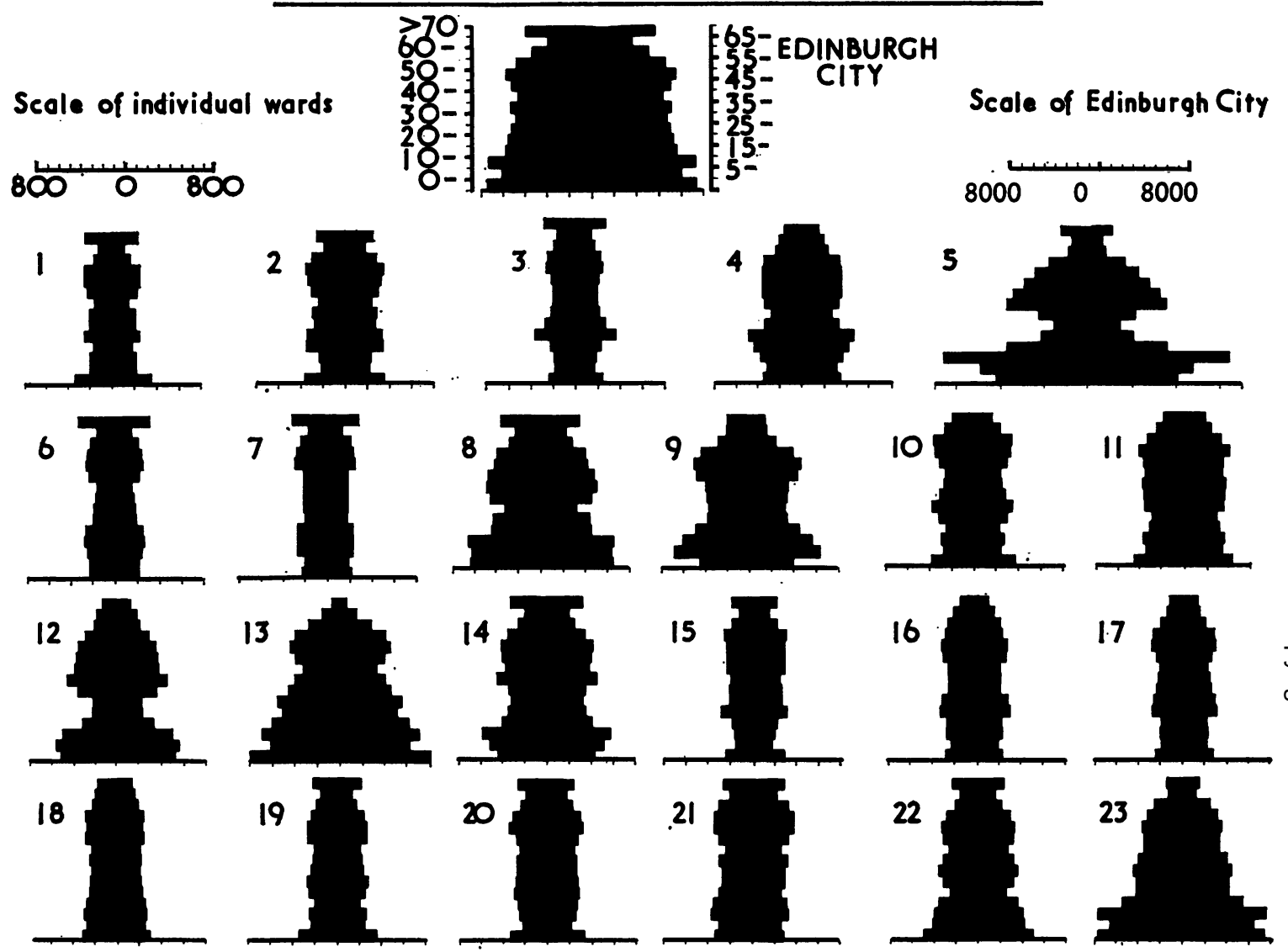

FIG. 1 Male population of Edinburgh, 1967, with histograms for individual electoral wards

tained from five or more cases this is shown in heavier type. In Table II the rates for gonorrhoea within the 15 to 44 and 20 to 24 year age groups have been calculated and the rank order is stated. High rates for the variables calculated were seen regularly in the wards in the centre of the city, namely St. Andrews (15), St. Giles (1), and Calton (17). Craigmillar (23) had a higher rank for females than for males.

Maps have been prepared (Fig. 6, p. 495) to show the infection rates for gonorrhoea in the 15 to 44 year age group in males and females. Variations in shading are used to denote the rate per 1,000 for the wards with a higher rate than the City as a whole.

It is appropriate to describe briefly the electoral wards which rank high in the various rates calculated and to give the main findings associated with each electoral ward:

\section{St. Giles (Electoral Ward 1)}

Figs 1 and 2 show that this is an electoral ward low in population, with few young children. It contains the Castle, Princes Street, Waverley Station, and the older parts of the town. It is a central area second in rank for gonorrhoea in males aged 20 to 24 years, and third in rank for gonorrhoea in females aged 15 to 44 years. The proportion of older men coming to the clinic from the St. Giles ward where five of Edinburgh's seven Common Lodging Houses are situated is higher than usual. The 'Total cases' rate in particular was markedly higher than the Edinburgh rate (Fig. 4, overleaf).

\section{Holyrood (Electoral Ward 2)}

Figs 1 and 2 show that this ward is similar to St. Giles (No. 1) though with a slightly larger population. It is sixth in rank for gonorrhoea in males and females aged 15 to 44 years, and third in rank for females aged 20 to 24 years. 


\section{ESTIMATED FEMALE POPULATION OF EDINBURGH (1967)}

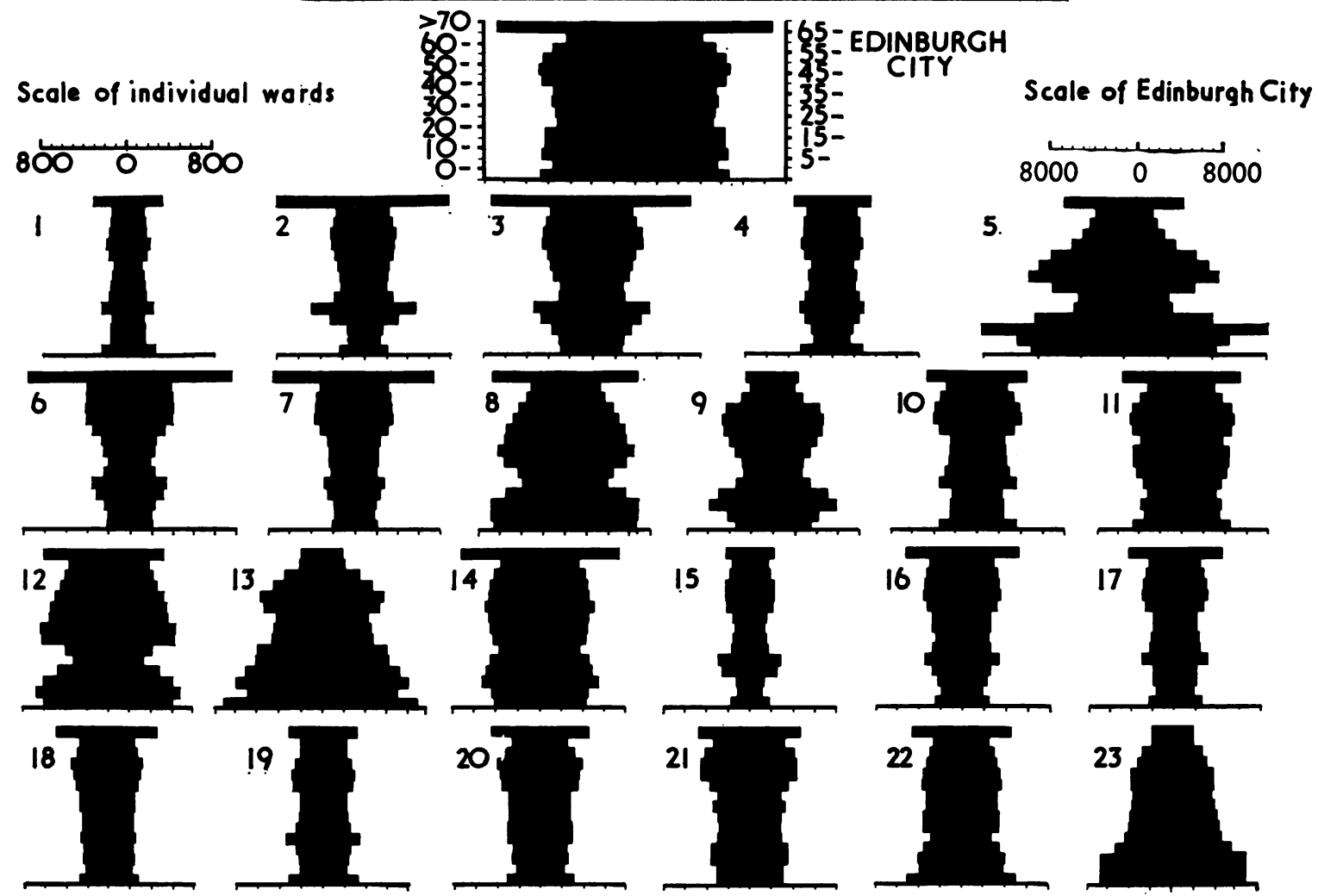

FIG. 2 Female population of Edinburgh, 1967, with histograms for individual electoral wards
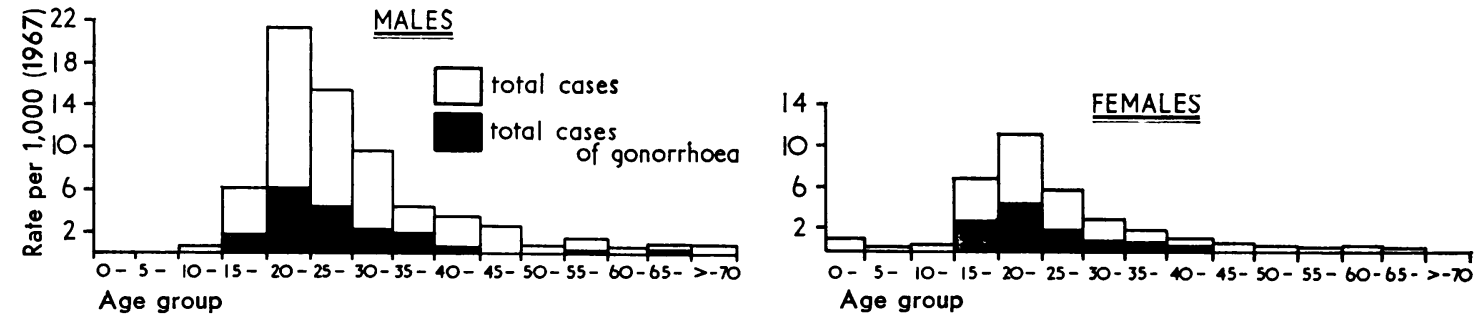

FIG. 3 Distribution of cases of gonorrhoea by age and sex

'Total cases' includes all new patients presenting at the clinic, and those returning after a risk of re-infection or with a further infection

'Total cases of gonorrhoea' includes first infections and re-infections 
TABLE II Rates per 1,000 of gonorrhoea by sex and age group in decreasing order of prevalence in individual wards, showing those above and below the rates for the city as a whole. Ward numbers are given in brackets.

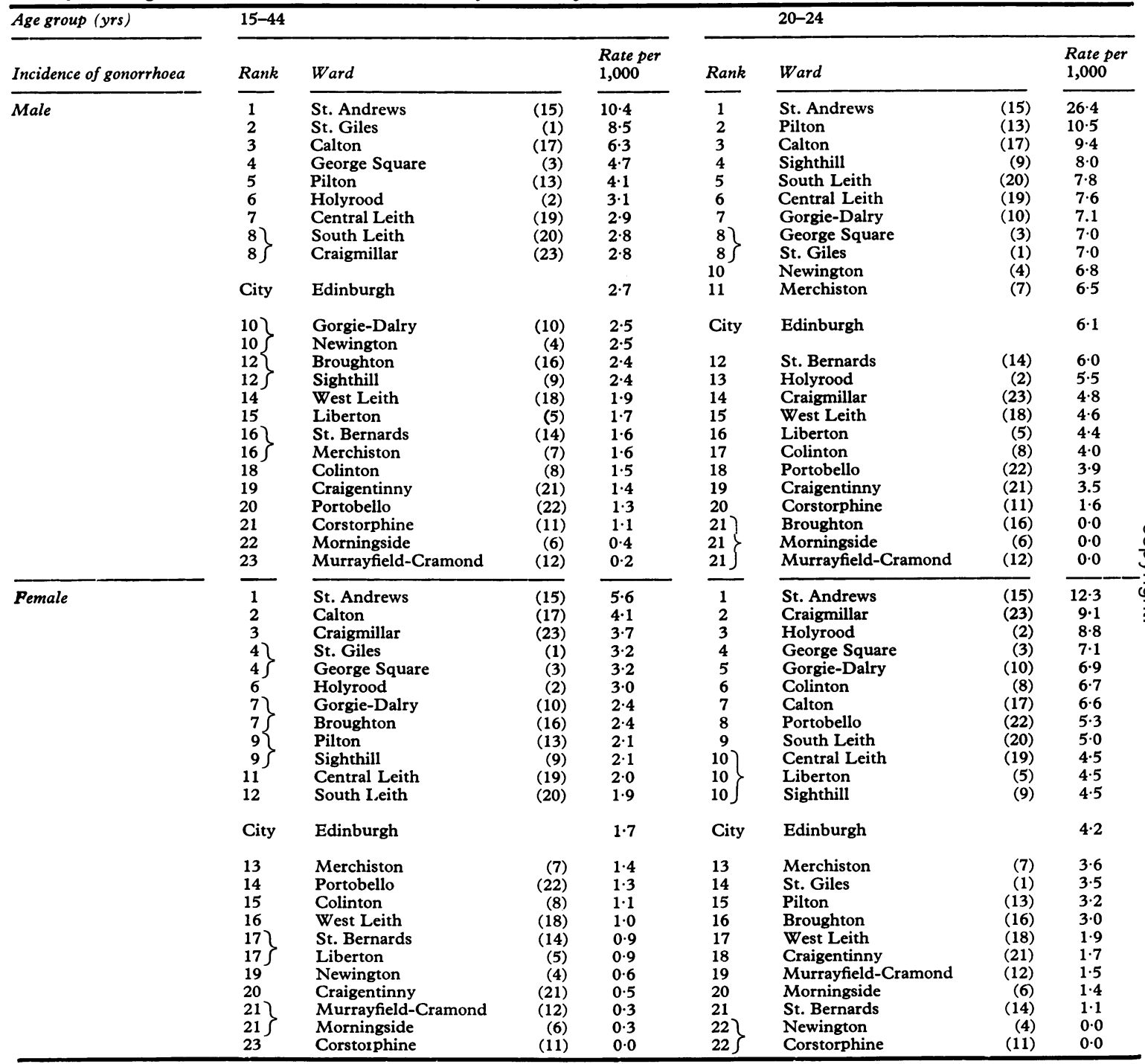

George Square (Electoral Ward 3)

Figs 1 and 2 show that this ward has a small population of men and is similar in size to Holyrood and St. Giles though it contains a much larger population of women. It contains the main parts of the University and probably houses a high proportion of students. It is equal fourth with St. Giles in rank for gonorrhoea in females aged 15 to 44 years and fourth in rank for females aged 20 to 24 years.

Pilton (Electoral Ward 13)

Figs 1 and 2 show that this is a ward with a high population of families with young children and with few old men and women. It contains large Corporation housing estates built after 1945. It is fifth in rank for gonorrhoea in males aged 15 to 44 years and second for males in the 20 to 24 year age group.

\section{St. Andrews (Electoral Ward 15)}

Figs 1 and 2 show that this ward has a small population. It contains centres of entertainment and many public houses. It is first in rank for gonorrhoea in males and females of all age groups; males in the 20 to 24 year age group have more than $2 \frac{1}{2}$ times the rate of the ward next in rank.

Calton (Electoral Ward 17)

Figs 1 and 2 show that this ward has a small population 
TOTAL CASES (MALES) RATE PER 1,000 (1967)

\begin{tabular}{|c|c|c|c|c|c|c|c|c|c|c|c|c|c|c|}
\hline & \begin{tabular}{|l|l|}
$0-6$ & $5-9$ \\
\end{tabular} & $10-16$ & 15-19 & $20-26$ & 25-29 & $30-34$ & $35-39$ & $60-46$ & $45-69$ & $50-56$ & $55-59$ & $60-66$ & $65-69$ & $70-$ \\
\hline$[$ Shy & & 0.1 & 6.1 & 21.6 & 15.5 & 9.9 & 4.4 & 3.4 & 2.6 & 0.7 & 1.4 & 0.6 & 1.0 & 0.9 \\
\hline 1 & & 2.7 & 15.8 & 45.6 & 31.9 & 20.1 & 14.6 & 7.9 & 16.3 & 1.8 & 10.5 & 2.1 & 100 & 8.5 \\
\hline 2 & & & 11.2 & 19.3 & 14.8 & 15.7 & 9.4 & 42 & 3.1 & 2.9 & & & 9.9 & \\
\hline 3 & & & 4.8 & 23.9 & 21.1 & 27.6 & 8.3 & 8.2 & & & 2.3 & 2.8 & & \\
\hline 6 & & & 3.8 & 30.7 & 31.9 & 9.5 & 0.6 & 3.5 & & & & & 2.5 & 3.5 \\
\hline 5 & & & 7.6 & 19.6 & 16.6 & 6.2 & 3.2 & & 3.2 & & & & & \\
\hline 6 & & & 2.4 & 9.9 & 10.3 & 11.1 & & 3.1 & & & & & & \\
\hline 7 & & & 4.5 & 21.7 & 6.4 & 2.7 & 2.6 & & & & & & & \\
\hline 8 & & & 4.0 & 16.1 & 9.8 & 5.9 & 3.5 & 2.8 & 2.1 & 1.1 & 1.6 & & & \\
\hline 9 & & & 7.3 & 12.6 & 9.1 & 6.2 & 4.6 & 4.5 & & 2.2 & 2.6 & & & \\
\hline 10 & & & 15.9 & 19.6 & 10.4 & 5.4 & 10.6 & 2.3 & 1.8 & & 3.2 & & 2.9 & \\
\hline 11 & & & 4.5 & 12.5 & 13.8 & 8.9 & 4.9 & 2.6 & & 1.1 & & & & \\
\hline 12 & & & 2.4 & 6.8 & 10.3 & 5.5 & 2.5 & 2.9 & i.o & & & & & \\
\hline 13 & & 0.6 & 7.7 & 16.5 & $\mid 11.0$ & 21.8 & 4.4 & 1.3 & 2.2 & & 1.0 & & 2.9 & \\
\hline 14 & & & 8.9 & 28.9 & 11.2 & 3.0 & 3.6 & 1.3 & 1.3 & & & & & \\
\hline 15 & & & $23.9 \mid$ & $|57.6|$ & $|30.0|$ & 27.9 & 12.6 & 16.7 & 9.0 & & & 3.4 & & \\
\hline 16 & & & 2.1 & 16.3 & 15.7 & 11.7 & 8.8 & 6.8 & 3.7 & & 1.9 & $2 \cdot 2$ & & \\
\hline 17 & & & 2.6 & 33.9 & 46.7 & 15.2 & 9.3 & 4.9 & 4.3 & 1.9 & 2.0 & & & \\
\hline 18 & & & 1.9 & 20.5 & 0.1 & & 2.3 & 4.8 & 4.2 & & 4.2 & & & \\
\hline 19 & & & 5.0 & 26.5 & 12.5 & 8.8 & 4.6 & 2.3 & & 1.0 & 2.3 & & & 4.6 \\
\hline 20 & & & 7.6 & 27.2 & 17.8 & 5.5 & & 4.2 & & & 1.6 & & & \\
\hline 21 & & & 1.5 & 26.0 & 16.0 & 5.3 & 1.6 & 4.1 & 4.8 & & & 1.6 & & 3.6 \\
\hline 22 & & & 2.9 & 13.6 & 7.8 & 5.7 & 1.6 & 1.9 & 3.1 & 1.5 & & & & \\
\hline 23 & & & 3.7 & 14.5 & 13.5 & 10.5 & 5.0 & 4.4 & 4.7 & 1.5 & & 2.0 & & \\
\hline
\end{tabular}

GONORRHOEA CASES (MALES) RATE PER 1000 (1967)

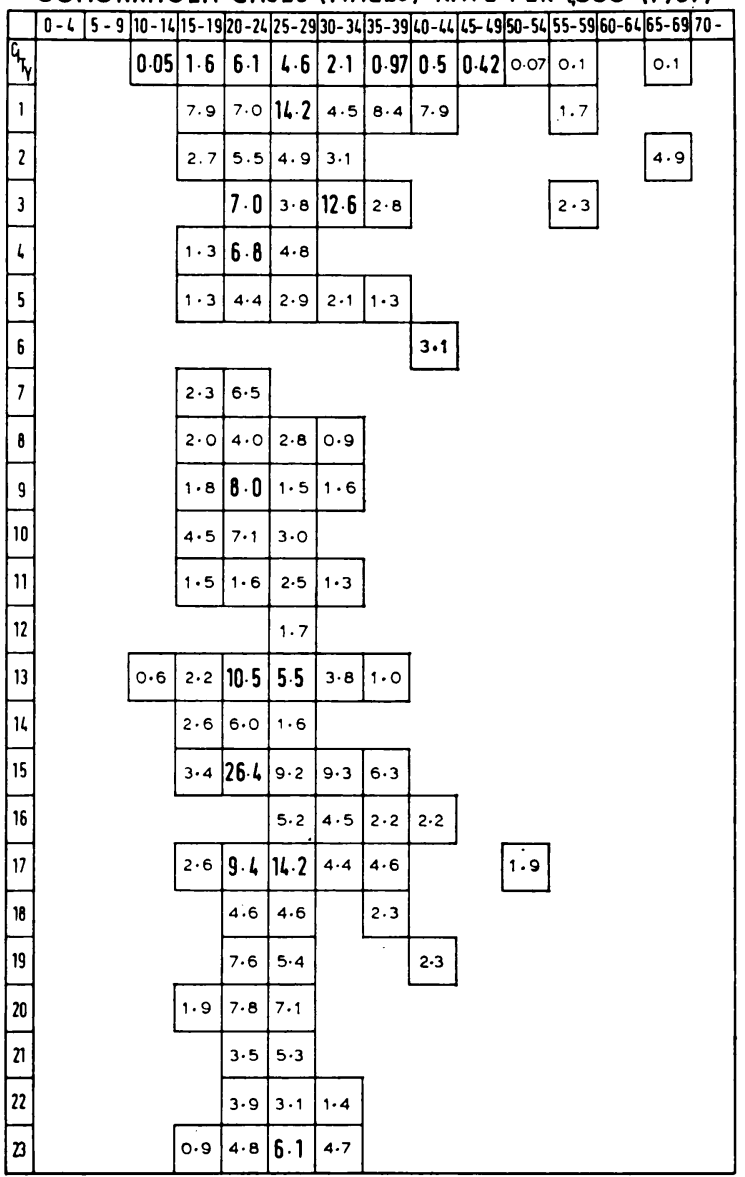

FIG. 4 Distribution of cases in males according to domicile

'Total cases' includes all new patients presenting at the clinic, and those returning after a risk of re-infection or with a further infection

'Gonorrhoea cases' includes all new patients presenting at the clinic with gonorrhoea and those returning with gonorrhoea Numbers in left-hand column in this Figure and in Fig. 5 (overleaf) are those of the municipal wards as defined in Table I. Rates for the City as a whole (CITY) are also given. Numbers in heavy type denote that rates have been calculated on five or more cases.

of all ages with a slight predominance of females above 70 years of age. It contains a confluence of main streets where there are also centres of entertainment. It is third in rank for gonorrhoea in males aged 20 to 24 and 15 to 44 years and second in rank for gonorrhoea in women aged 15 to 44 years.

\section{Craigmillar (Electoral Ward 23)}

Figs 1 and 2 show that this ward has a high population, particularly of families with young children, but few old men and women. It contains large pre-war Corporation housing estates. It is third in rank for gonorrhoea in females aged 15 to 44 years and second for females in the 20 to 24 year age group.

\section{Discussion}

Data on the incidence of sexually transmissible disease in Great Britain have been published regularly over the past 14 years by the British Cooperative Clinical Group, which has recorded an unwelcome increase, particularly in respect of gonorrhoea. The case rate for the country as a whole increased from 127.8 per 100,000 in 1960 to 166.4 in 1968 (British Co-operative Clinical Group, 1962 and 1970).

A higher incidence was noted in the larger town and cities, and in England and Wales the incidence of 
TOTAL CASES (FEMALES) RATE PER I,000 (1967)

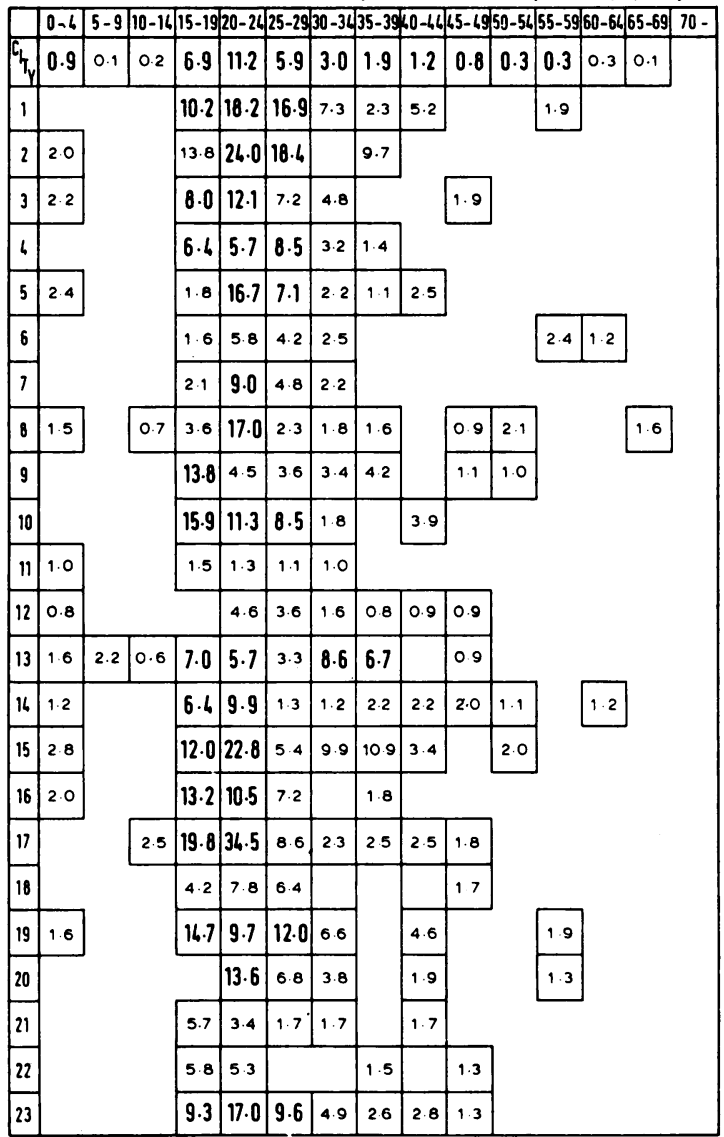

GONORRHOEA CASES (FEMALES) RATE PER 1,000 (1967)

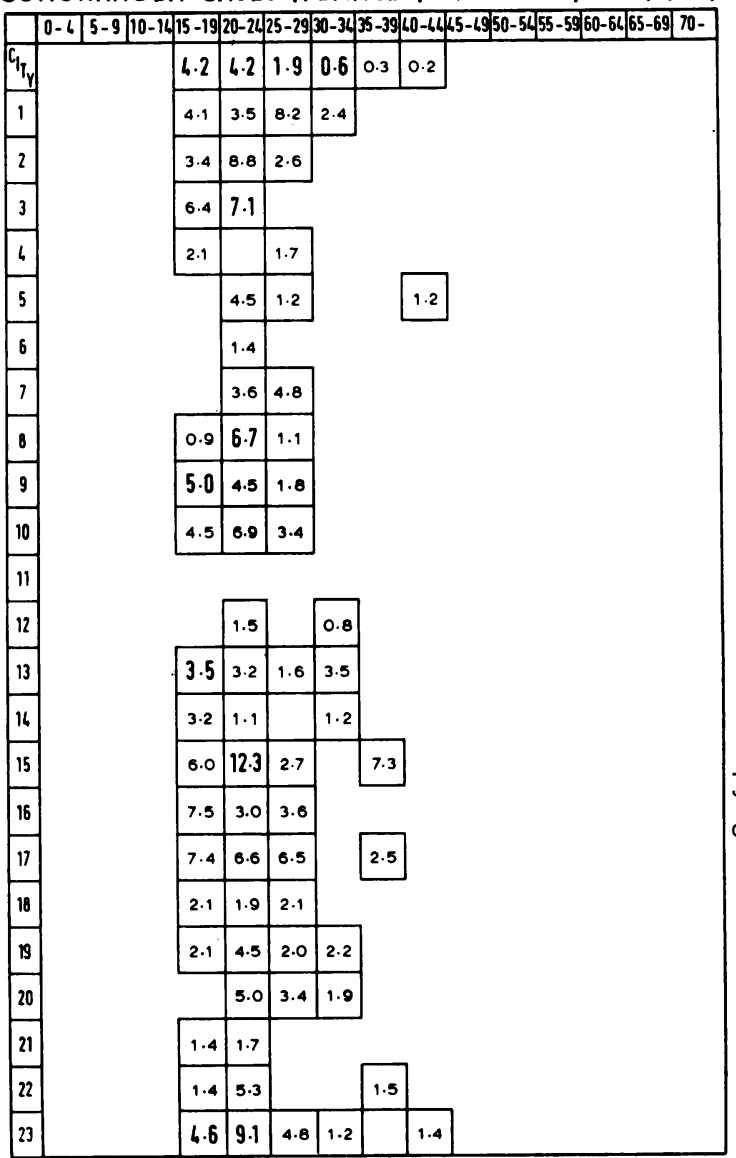

FI G. 5 Distribution of cases in females according to domicile

'Total cases' includes all new patients presenting at the clinic, and those returning after a risk of re-infection or with a further infection

'Gonorrhoea cases' includes all new patients presenting at the clinic with gonorrhoea, and those returning with gonorrhoea

infection among immigrants is a prominent feature. In Scotland this aspect is of less importance; in 1968 it was noted that 98.7 per cent. of the female and 86.9 per cent. of the male patients attending Scottish clinics were born in the United Kingdom (British Co-operative Clinical Group, 1970).

This present study deals with sexually transmissible infections in Edinburgh and more detail has been provided by giving rates for each municipal ward within the City. The quality of the data has been indicated and emphasis has been placed on results based on five or more cases in any particular age group in each ward.

It should be understood that problems of selection may occur. In connection with 'Total cases' in females, for example, a figure which includes a wide variety of infections such as trichomoniasis and genital warts, some general practitioners may refer patients to a special clinic whereas others will send them to a gynaecological outpatients department. Selection may also occur because some patients will tend to return for immediate help to a clinic to which they have easy access and with which they are familiar.

With trichomoniasis in females it has been shown that there is a tendency to over-diagnosis in outpatients (Robertson, Lumsden, Fraser, Hosie, and Moore, 1969). Problems also occur in relation to accuracy of diagnosis of other conditions. With gonorrhoea in males diagnostic accuracy is high, but in women doctors tend to make an epidemiological 


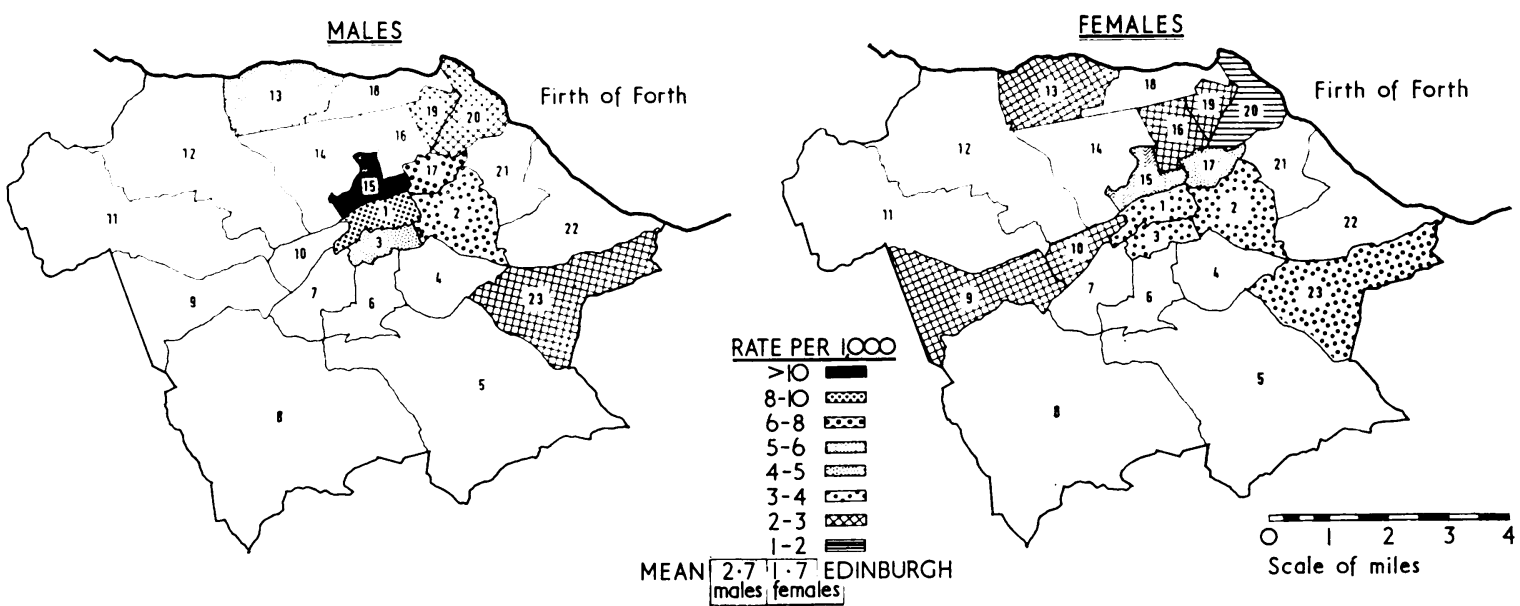

FIG. 6 Map of Edinburgh showing rates per 1,000 for gonorrhoea in males and females in wards with a higher rate than the city as a whole. Unshaded areas have rates less than the average city rate

diagnosis when the patient has had recent coitus with an infected consort. Confirmation of the diagnosis of gonorrhoea by culture was obtained in 90.2 per cent. of men and $76 \cdot 1$ per cent. of women.

The municipal wards of Edinburgh have distinct characteristics and particular medical problems. Craigmillar (No. 23), for example, carries a high rank for attempted suicide (SECOND), for juvenile delinquency (FIRST), for children being taken into care of the local authority (FIRST), for overcrowding (FIRST), for infant mortality (SECOND), for council houses (FIRST), and for referrals by the Royal Scottish Society for the Prevention of Cruelty to Children-R.S.S.P.C.C.-(FIRST) (Philip and McCulloch, 1966). We have found it to carry a high rank, particularly for females, in that it is third for gonorrhoea in the 15 to 44 year age group and second in the 20 to 24 year age group.

The illegitimacy index shows a localization similar to that of venereal disease. The first five wards in 1968 were, first St. Andrews (14.0 per 1,000), second George Square (13.6 per 1,000), third Central Leith $(12.6$ per 1,000$)$, fourth St. Giles $(12 \cdot 0$ per $1,000)$, and fifth Calton $(11.4$ per 1,000$)$ (Short, personal communication). In our survey all except Central Leith come within the first five in the sexually active 15 to 44 year age group in females, and St. Andrews ward has the highest incidence of gonorrhoea in the City.

Calton (No. 17) shares with other central wards, St. Andrews (No. 15) and St. Giles (No. 1), the main centres for entertainment, and these wards rank high for gonorrhoea rate in both sexes. Calton (No. 17) is third in rank for self-poisoning and fourth for children being taken into care. St. Giles (No. 1) is first in rank for self-poisoning and second for juvenile delinquency, children taken into care, and R.S.S.P.C.C. referrals (Philip and McCulloch, 1966). These three wards are first, second, and third for gonorrhoea in males in the 15 to 44 year age group, first, fourth, and second for gonorrhoea in females.

Philip and McCulloch (1966) criticized the common practice of describing unfavourable environment by subjective terms which may confuse attempts to define aetiological factors in psychiatric illness. They have shown the use of elementary linkage analysis in the endeavour to demonstrate association between variables such as high rates for self-poisoning, children in care, R.S.S.P.C.C. referrals, and absence from school. The problem of sexually transmissible disease is complex but there is evidence to suggest that it may be linked to other manifestations of family inadequacy.

A higher proportion of older men come to the clinic from St. Giles ward (Fig. 4) with non-specific complaints which may be linked to faulty hygiene. In 1967 this ward contained five of the seven Common Lodging Houses for men, which are controlled by Edinburgh City byelaws. These five lodging houses held 87 per cent. of 815 male beds in the City (Medical Officer of Health, City of Edinburgh; 1969) and housed about a third of the males over the age of 45 years in this ward. They cater for men who require cheap lodging with the least amount of restriction (Scott, Gaskell, and Morrell, 1966), and many such men appear to be unable to establish personal relationships or to hold employment of any 
permanence (Morrell, 1967). It may be that similar problems affect the older men from this area who attend the clinic. Persons from lodging houses appear to have difficulty in making and keeping appointments; they regard this discipline as repugnant and tend to react aggressively (Morrell, 1967). This factor should be taken into consideration when proposals are made to develop rigid appointment systems in special clinics or elsewhere, as these patients have many difficulties and are not catered for satisfactorily by the National Health Service (Gaskell, 1969).

These data on the infection rates can only begin to define the epidemiological problems of the City. Information of this kind has been valuable in persuading the Regional Hospital Board to retain the clinic in St. Giles ward (No. 1) at the Royal Infirmary and not to transfer it to the Western General Hospital in St. Bernards ward (No. 14) in an area more remote from the centre of the City and less accessible by public transport. More information is required to define the problems of Edinburgh and to identify those who suffer other as yet undefined handicaps who may be a reservoir of sexually transmissible infection. Data on the incidence of such diseases in the country as a whole are valuable, but local epidemiological studies are more likely to disclose the particular difficulties of a given area.

\section{Summary}

A population estimate for 1967 was prepared for the City of Edinburgh by calculating the percentage change in the electorate and applying this to the 1961 census figures.
In Edinburgh during 1967, 971 cases in males and 529 cases in females were examined at the Royal Infirmary Special Clinic. Gonorrhoea was diagnosed on 240 occasions in men and 159 in women. In the City as a whole the rate per 1,000 persons in the 15 to 44 year age group was 2.7 for males and $1 \cdot 7$ for females.

Certain central parts of the City showed rates for gonorrhoea which were much higher than the City rate.

Areas with high rates for major social problems tend also to have high rates for sexually transmissible infections. The highest rates of infection were found in the City centre and around the docks.

Thanks are given to the clinicians and other staff of Wards 45 and 46 of the Edinburgh Royal Infirmary. Particular thanks are expressed for the able technical assistance of Mr. R. J. Pitcairn.

This research was supported by the Scottish Home and Health Department as part of a wider epidemiological study.

\section{References}

Adams, A. (1967) Med. F. Aust., 1, 145

British Cooperative Clinical Group (1962) Brit. $\mathcal{F}$. vener. Dis., 38, 1

$\longrightarrow \longrightarrow-1$ (1968) Ibid.: 44, 305 (1970) Ibid., 46, 62

Gaskell, P. G. (1969) Health Bulletin (issued by Chief Medical Officer of Scottish Home and Health Department), 27, 13

GILL, G. K., and Gould, J. D. M. (1967) Unpublished results of undergraduate research project

\section{APPENDIX B}

Estimated population of 23 wards of the City of Edinburgh, by age group and sex, 1967

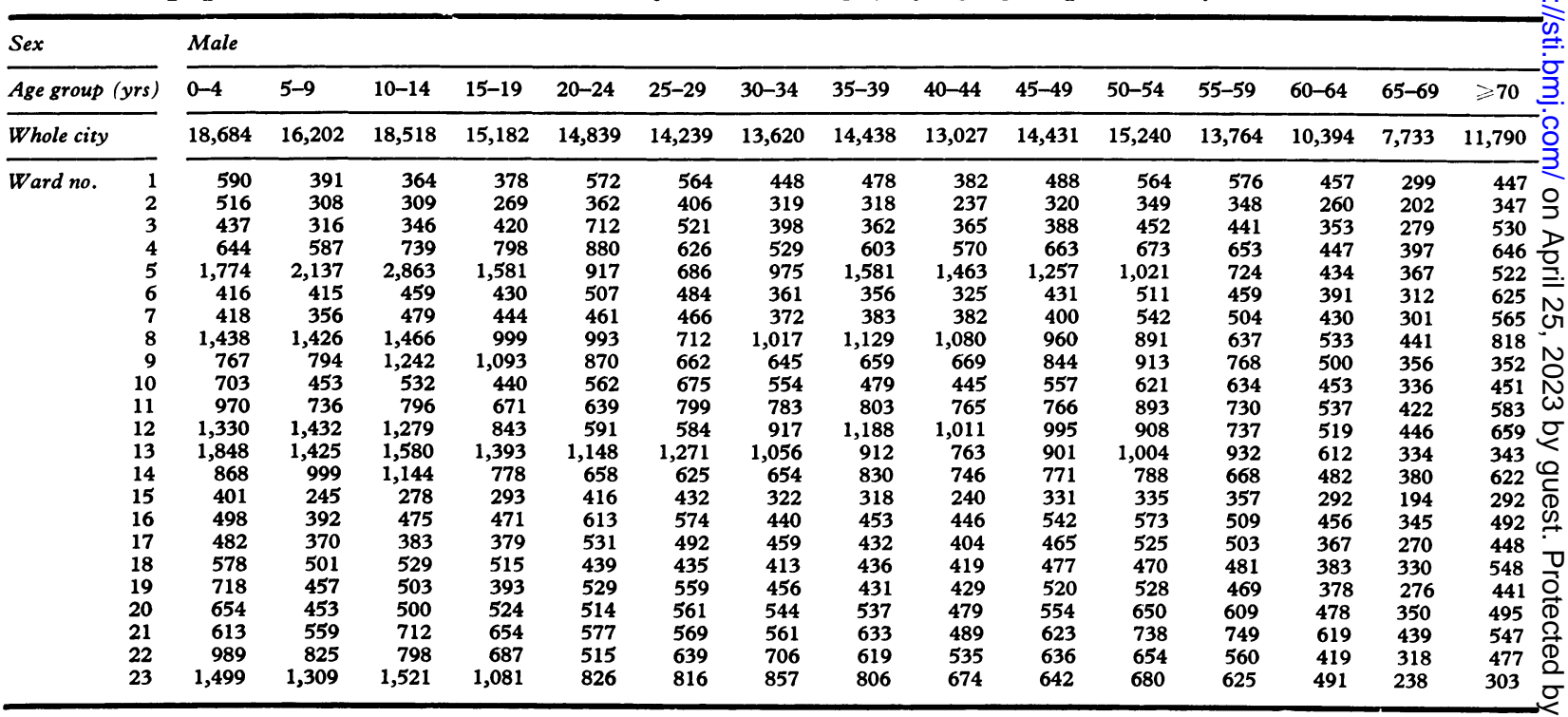


Medical Officer of Heal th, City of Edinburgh (1969) 'Annual Report of the Health and Social Services Department for the Year 1968 ', p. 120.

MorRell, D. C. (1967) Scot. med. f., 12, 171

Philip, A. E., and McCulloch, J. W. (1966) Brit. F. prev. soc. Med., 20, 122

Registrar General for SCotland (1963) 'Census 1961 Scotland, County Report, vol. 1, part 1, City of Edinburgh'. H.M.S.O., Edinburgh

Robertson, D. H. H. (1969) Brit. F. vener. Dis., 45, 129

— and GeORGe, G. (1970) Ibid., 46, 46

- Lumsden, W. H. R., Fraser, K. F., Hosie, D. D., and MOORE, D. M. (1969) Ibid., 45, 42

SCott, R., Gaskell, P. G., and Morrell, D. C. (1966) Brit. med. F., 2, 1561

\section{La gonococcie à Edimbourg} SOMMAIRE

Une estimation de la population de 1967 a été établie pour la Cité d'Edimbourg en calculant le pourcentage de changement des listes électorales et en appliquant celui-ci aux chiffres du recensement de 1961.

Pendant l'année 1967, à Edimbourg, on a examinè à la Royal Infirmary Special Clinic 971 hommes et 529 femmes. La gonococcie a été reconnue 240 fois chez les hommes et 159 fois chez les femmes. Pour la Cité dans son ensemble, le taux pour 1.000 personnes, dans le groupe de 15 à 44 années d'âge, fut de 2,7 pour les hommes et de 1,7 pour les femmes.

Les taux de gonococcie furent beaucoup plus élevés dans certaines parties du centre de la Cité que le taux général de la Cité.

Les zones ayant un haut taux de problèmes sociaux majeurs tendent aussi à avoir un haut taux d'infections transmises par voie sexuelle. Les plus hauts taux d'infection ont été trouvés au centre de la Cité et autour des docks.

\section{APPENDIX A}

\section{Seamen's Dispensary, Leith}

In the electoral ward of Central Leith (No. 19) there is a Seamen's Dispensary primarily intended to serve merchant seamen and restricted to male patients, which is open from 4 to 6 p.m. on Mondays and Thursdays. A total of 211 cases (all diagnoses) was seen during 1967 with 111 cases in males having residence in Edinburgh and comprising 10.26 per cent. of the total males seen at both clinics, namely at the Seamen's Dispensary in Leith and at Edinburgh Royal Infirmary. The cases of gonorrhoea in males seen at the Seamen's Dispensary at Leith totalled $46 ; 27$ of the men were domiciled in Edinburgh and comprised $10 \cdot 11$ per cent. of the total seen at both clinics. Eleven of the 27 men (40.74 per cent.) were domiciled in Central Leith (No. 19) and Pilton (No. 13). The remaining sixteen cases $(59.26$ per cent.) were scattered throughout the City.

The data for Edinburgh Royal Infirmary are seen to be representative of the City as a whole with the exception of Pilton (No. 13) and Central Leith (No. 19) where the rates for males are increased as follows:

\section{Gonorrhoea cases}

Pilton (No .13) increase $=29.86$ per cent. Central Leith (No. 19) increase $=17.65$ per cent.

If these data are included a minor change in the final rank order is noted as follows:

Gonorrhoea cases

Pilton (No. 13) Rank order 4th, Rate 5.35 per 1,000 males

Central Leith (No. 19) Rank order 6th, Rate 3.36 per 1,000 males

\begin{tabular}{|c|c|c|c|c|c|c|c|c|c|c|c|c|c|c|}
\hline \multicolumn{15}{|l|}{ Female } \\
\hline $0-4$ & 5-9 & $10-14$ & $15-19$ & $20-24$ & $25-29$ & $30-34$ & $35-39$ & $40-44$ & $45-49$ & $50-54$ & $55-59$ & $60-64$ & $65-69$ & $\geqslant 70$ \\
\hline 17,785 & 15,375 & 17,592 & 16,626 & 16,705 & 14,279 & 14,490 & 15,438 & 14,913 & 17,085 & 17,812 & 16,903 & 14,827 & 12,542 & 23,569 \\
\hline 566 & 325 & 374 & 484 & 599 & 485 & 410 & 419 & 382 & 503 & 560 & 528 & 524 & 442 & 697 \\
\hline 488 & 300 & 304 & 289 & 464 & 378 & 329 & 307 & 254 & 365 & 401 & 376 & 352 & 302 & 641 \\
\hline 446 & 293 & 319 & 617 & 988 & 545 & 413 & 436 & 457 & 530 & 587 & 602 & 561 & 504 & 1,116 \\
\hline 566 & 592 & 738 & 923 & 1,052 & 585 & 594 & 706 & 758 & 795 & 945 & 930 & 814 & 741 & 1,781 \\
\hline 1,687 & 1,955 & 2,658 & 1,639 & 890 & 837 & 1,309 & 1,796 & 1,585 & 1,326 & 961 & 774 & 624 & 523 & 1,115 \\
\hline 412 & 406 & 477 & 607 & 705 & 474 & 391 & 471 & 518 & 676 & 803 & 820 & 807 & 793 & 1,918 \\
\hline 419 & 342 & 368 & 460 & 553 & 414 & 436 & 444 & 484 & 613 & 732 & 708 & 680 & 620 & 1,467 \\
\hline 1,309 & 1,363 & 1,360 & 1,115 & 762 & 856 & 1,134 & 1,248 & 1,131 & 1,080 & 948 & 850 & 713 & 625 & 1,346 \\
\hline 679 & 844 & 1,198 & 1,009 & 674 & 558 & 596 & 703 & 808 & 916 & 946 & 843 & 585 & 400 & 483 \\
\hline 700 & 471 & 476 & 439 & 708 & 583 & 537 & 516 & 506 & 670 & 792 & 780 & 670 & 568 & 940 \\
\hline 926 & 697 & 752 & 653 & 727 & 850 & 889 & 905 & 771 & 930 & 970 & 938 & 792 & 607 & 1,086 \\
\hline 1,194 & 1,326 & 1,205 & 952 & 650 & 816 & 1,251 & 1,264 & 1,091 & 1,069 & 1,011 & 906 & 837 & 745 & 1,419 \\
\hline 1,811 & 1,361 & 1,584 & 1,439 & 1,230 & 1,184 & 923 & 898 & 846 & 1,053 & 1,131 & 906 & 657 & 412 & 374 \\
\hline 838 & 888 & 1,078 & 945 & 914 & 743 & 856 & 909 & 937 & 998 & 924 & 915 & 828 & 704 & 1,442 \\
\hline 358 & 221 & 250 & 498 & 568 & 366 & 303 & 275 & 293 & 411 & 481 & 486 & 374 & 347 & 655 \\
\hline 482 & 360 & 451 & 532 & 665 & 554 & 470 & 543 & 564 & 624 & 708 & 680 & 658 & 580 & 1,053 \\
\hline 485 & 354 & 393 & 401 & 609 & 462 & 431 & 399 & 392 & 557 & 598 & 593 & 551 & 485 & 866 \\
\hline 582 & 434 & 482 & 475 & 510 & 467 & 467 & 490 & 511 & 583 & 618 & 646 & 575 & 534 & 988 \\
\hline 630 & 415 & 454 & 475 & 667 & 502 & 457 & 440 & 433 & 558 & 569 & 525 & 492 & 417 & 619 \\
\hline 624 & 441 & 513 & 490 & 590 & 587 & 512 & 515 & 509 & 690 & 724 & 782 & 635 & 541 & 954 \\
\hline 596 & 504 & 698 & 703 & 582 & 560 & 574 & 686 & 562 & 750 & 886 & 884 & 815 & 642 & 893 \\
\hline 1,006 & 787 & 790 & 685 & 565 & 704 & 692 & 665 & 664 & 725 & 713 & 653 & 585 & 501 & 902 \\
\hline 1,393 & 1,393 & 1,385 & 1,079 & 881 & 832 & 809 & 775 & 725 & 754 & 765 & 657 & 554 & 295 & 363 \\
\hline
\end{tabular}

